THÉMATA. Revista de Filosofía

$\mathrm{N}^{\circ} 51$, Enero-junio (2015) pp.: 189-206

ISSN: 0212-8365 e-ISSN: 2253-900X

doi: 10.12795/themata.2015.i51.10

\title{
NIETZSCHE CONTRA LA STOA: \\ LA AFIRMACIÓN DE LA VIDA CONTRA LA \\ RENUNCIA ESTOICA
}

\section{NIETZSCHE CONTRA THE STOA: THE AFFIRMATION OF LIFE AGAINST THE STOIC RENUNCIATION}

\author{
Maybeth Garcés Brito ${ }^{1}$ \\ Universidad Simón Bolívar (Venezuela)
}

Recibido: 30-05-2014

Aceptado: 04-09-2014

\begin{abstract}
Resumen: En este trabajo se propone analizar la valoración que hace Nietzsche de la filosofía estoica a lo largo de su obra. A pesar de los puntos de encuentro que se han establecido entre los estoicos y Nietzsche, especialmente a partir de la doctrina del eterno retorno y del amor fati, se plantea que existen diferencias irreconciliables entre ambas filosofías que, con frecuencia, han sido dejadas a un lado y cuyo análisis, por otra parte, nos permite una nueva comprensión de la Stoa. Para argumentar esto, nos centraremos en las diferencias que hay entre la concepción nietzscheana y la estoica de la filosofía como terapia, el lugar que ocupan las pasiones en dichas filosofías como medicinas, y las críticas que hace el filósofo alemán al optimismo metafísico y a la pretensión del estoicismo de conseguir la felicidad.
\end{abstract}

Palabras-clave: Nietzsche, estoicismo, renuncia, pasiones, amor fati.

\begin{abstract}
This paper analyzes the Nietzsche's evaluation of the stoic philosophy through his works. Despite the meeting points that have been established between the stoics and Nietzsche, specially based on the doctrine of the eternal recurrence and the amor fati, it's posited that there are irreconcilable differences between both philosophies that have often been left aside and which analysis, on the other hand, give us a new comprehension of the Stoa. To argue this, we will focus on the differences between the Nietzsche's and Stoic conception of the philosophy as therapy, the place of the passions in those philosophies as medicines and the critiques of the metaphysical optimism and the Stoic claim to achieve happiness realized by the German philosopher.
\end{abstract}

Key-words: Nietzsche, stoicism, renounce, passions, amor fati.

[1] (maybeth@gmail.com) Licenciada en Filosofía (Universidad Católica Andrés Bello), Caracas, Venezuela. Actualmente cursando la Maestría en Filosofía en la Universidad Simón Bolívar, Caracas. 
En el hecho de que hayáis desesperado hay mucho que honrar.

Porque no habéis aprendido cómo resignaros, no habéis aprendido las pequeñas corduras. -Asi habló Zaratustra, Nietzsche.

El estoicismo sólo podía surgir en una época de temor y servidumbre universales. -Fenomenología del espíritu, Hegel.

\section{La filosofía como terapia}

Es innegable que las ideas estoicas influyeron en el pensamiento nietzscheano. El filósofo alemán dedica varios pasajes de su obra a la reflexión sobre los postulados estoicos y muestra, en algunas ocasiones, un profundo respeto por filósofos como Epicteto y Séneca. Su pensamiento "auténticamente abismal", el del eterno retorno, guarda una estrecha relación con la concepción estoica que, a su vez, siguió la doctrina de Heráclito². A primera vista, la famosa fórmula nietzscheana del amor fati no pareciera diferir en mucho del ideal del sabio estoico que acepta el destino en cuanto manifestación del logos universal. Incluso en un aforismo de Más allá del bien y del mal, Nietzsche se denomina a sí mismo y a los "espíritus libres", aquellos futuros lectores que él vislumbraba, "los últimos estoicos"3. Autores como Ure han puesto de relieve la afinidad que hay entre la concepción nietzscheana de la filosofía como arte de vivir o medicina y el estoicismo ${ }^{4}$. Por su parte, Nussbaum sostiene que el proyecto filosófico de Nietzsche tiene como objetivo rescatar los valores estoicos del autodominio y autoformación fuera del contexto cristiano y romano ${ }^{5}$. Como podemos ver, es frecuente hallar en el pensamiento nietzscheano rasgos en común con los filósofos del Pórtico. Sin embargo, como señala Nabais, no hay un estudio sistemático de la relación entre Nietzsche y el estoicismo ${ }^{6}$,

[2] "La doctrina del «eterno retorno», es decir, del ciclo incondicional, infinitamente repetido, de todas las cosas, esta doctrina de Zaratustra podría, en definitiva, haber sido enseñada también por Heráclito. Al menos la Estoa, que ha heredado de Heráclito casi todas sus ideas fundamentales, conserva huellas de esa doctrina”. F. Nietzsche, Ecce Homo, Madrid: Alianza, 2006, p. 79.

[3] F. Nietzsche, Más allá del bien y del mal, Madrid: Alianza, 2007, 227, p. 185.

[4] Cfr. M. Ure, "Nietzsche's Free Spirit Trilogy and Stoic Therapy" en Journal of Nietzsche Studies, No. 38, 2009, pp. 60-84. Asimismo, Elventon sostiene que Nietzsche, al concebir la filosofía como eine Kunst des Lebens, se inscribe en la tradición estoica; aunque también señala que su pensamiento mantiene grandes diferencias con la Stoa. Cfr. R. Elventon, "Nietzsche's Stoicism: The Depths Are Inside" en Nietzsche and Antiquity, editado por Paul Bishop, Rochester, NY: Camden House, 2004, p. 192 y ss.

[5] Cfr. M. Nussbaum, "Pity and Mercy: Nietzsche's Stoicism" en Nietzsche, Genealogy, Morality, editado por Richard Schacht, Berkeley: University of California Press, 1994, p. 140.

[6] Cfr. N. Nabais, "Nietzsche and Stoicism" en Nietzsche and the Metaphysics of the Tragic, Continuum: London/New York, 2002, p. 87.

THÉMATA. Revista de Filosofía, Nº51 enero-junio (2015) pp.: 189-206 doi: 10.12795/themata.2015.i51.10 
la mayoría de los estudios que se encuentran hacen énfasis en los puntos comunes y, a menudo, dejan a un lado las importantes diferencias que hay entre ambas filosofías.

Según Ure, la posición de Nietzsche con respecto al estoicismo se puede dividir en dos fases: la de su etapa juvenil, en la década de 1870, cuando asume la filosofía como una medicina o un arte de vivir, muy cercano al de la terapia estoica; y la etapa que comienza en 1880, en la que Nietzsche comenzó a expresar serias dudas en relación con el modelo terapéutico estoico y su concepción de eudaimonía ${ }^{7}$. Las posteriores críticas que le hace Nietzsche al estoicismo tienen como eje central la concepción estoica de las pasiones y su intento por eliminarlas. Pero, a pesar de estas críticas, Ure sostiene que Nietzsche fracasó en su intento de ir más allá del estoicismo y que su doctrina del amor fati no es más que un estoicismo "cósmico", sólo que no se percató de ello ${ }^{8}$. No obstante, como más adelante expondremos, no puede inscribirse a Nietzsche en el marco del pensamiento estoico ${ }^{9}$, pues este afirma que no existe un orden natural, critica la pretensión por eliminar las pasiones "negativas" o violentas del estoicismo y el talante eudemonista de las filosofías morales antiguas.

Ciertamente, Nietzsche concibe la filosofía como una suerte de medi$\operatorname{cina}^{10}$. Ya en los fragmentos póstumos de 1872, Nietzsche planteaba que el filósofo debe ser un "médico de la cultura"11, cuya tarea es diagnosticar lo que es perjudicial para la vida y para la cultura (esta es una de las preocupaciones fundamentales de las Consideraciones intempestivas). Aunque el pensamiento nietzscheano afrontó una crisis que se materializó con la publicación de Huma-

[7] Cfr. M. Ure, op. cit., p. 64 y ss.

[8] "Nietzsche failed to see how his own doctrines of amor fati and eternal recurrence borrow directly from what I have called this cosmic version of Stoicism and, importantly, how they too hinge on achieving a certain kind of indifference" M. Ure, op. cit., p. 74.

[9] Para los fines de este trabajo, no haremos distinción entre la tradición estoica griega y la romana. Con ello no buscamos tratar la Stoa como un todo, pues incluso dentro de la tradición griega, por ejemplo Zenón y Crisipo, encontramos diferencias en el tratamiento de ciertos problemas. Procederemos así por la forma en la que Nietzsche aborda cuestiones centrales del estoicismo que, a nuestro juicio y como sustentaremos más adelante, comparten pensadores griegos y romanos, como la concepción de la filosofía en tanto medicina o terapia, el optimismo cosmológico y el carácter eudemonista de la filosofía. Como sostiene Sandbach a propósito de los estoicos romanos, "[a]lthough they are one-sided, their personalities come out strongly in their books and secured them many readers until recent times. Very different from one another, they share a common outlook. They have a minimal interest in anything but ethics and see in Stoic philosophy an established system of beliefs that could guide, comfort, and support a man in the difficulties and dangers of life" F.H. Sandbach, The stoics, $2^{\text {a }}$ edición, Idianapolis: Hackett, 1989, p. 17. Cursivas nuestras.

[10] Estudios recientes han resaltado este aspecto de la filosofía nietzscheana. Véase, por ejemplo, H. Hutter (ed), Nietzsche's Therapeutic Teaching, New York: Bloomsbury, 2013.

[11] Cfr. F. Nietzsche, Fragmentos póstumos (1869-1874), Madrid: Tecnos, 2010, 23 [15], p.434. En otro fragmento póstumo de 1873, Nietzsche señala que: "la filosofía debe ser una alianza de fuerzas que unan, como un médico de la cultura" Ibid., 30 [8], p. 558.

THÉMATA. Revista de Filosofía, No51 enero-junio (2015) pp.: 189-206 doi: 10.12795/themata.2015.i51.10 
no, demasiado humano ${ }^{12}$, esta concepción del filósofo como "médico" no cambió en sus obras posteriores. En La ciencia jovial, por ejemplo, escribe:

Todavía espero que un médico filósofo, en el sentido excepcional de la palabra - uno que haya de dedicarse al problema de la salud total del pueblo, del tiempo, de la raza, de la humanidad-tendrá alguna vez el valor de llevar mi sospecha hasta su extremo límite y atreverse a formular la proposición: en todo el filosofar nunca se ha tratado hasta ahora de la «verdad» sino de algo diferente, digamos de la salud, del futuro, del crecimiento, del poder, de la vida... ${ }^{13}$

Asimismo, en Más allá del bien y del mal, Nietzsche se refiere a "nosotros", es decir, a sí mismo y a los filósofos del futuro que él esperaba que aparecieran y comprendieran su obra, como "médicos" ${ }^{14}$. Pero, ¿esto nos autoriza a inscribir a Nietzsche en la tradición estoica? ¿Acaso la tarea de estos "médicos" que propuso el filósofo alemán es la misma que la del sabio estoico? ¿Buscan los estoicos y Nietzsche "curar" la misma enfermedad? ¿En qué medida ambas filosofías son terapias?

Como es sabido, el estoicismo tiene origen como movimiento filosófico en un contexto de crisis: el de la disolución de la polis. Si antes el ciudadano hallaba identidad y seguridad en la polis, ahora, por primera vez, el individuo tiene que enfrentar sus problemas en un diálogo a solas consigo mismo. En este escenario, la filosofía se convierte en una suerte de medicina o terapia que, de acuerdo con los postulados estoicos, es capaz de curar las enfermedades del alma, productos de una incorrecta evaluación en nuestros juicios y de pasiones desbordadas. Así, Marco Aurelio afirma que la filosofía es la que puede "preservar el guía interior, exento de ultrajes y de daño, dueño de placeres y penas"15; Epicteto, por otro lado, dice que la escuela del filósofo es un "hospital"

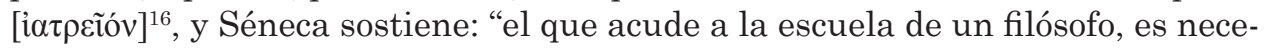
sario que todos los días obtenga algún provecho: que regrese a casa o más sano o más sanable"17. La analogía entre medicina y filosofía, como vemos, es usual en el estoicismo.

Ahora bien, ¿qué quiere decir Nietzsche cuando afirma que el filósofo debe ser un "médico de la cultura"? Como ya hemos señalado antes, dicha expresión aparece desde sus primeros escritos juveniles y, en cierta forma, anticipa una de las cuestiones centrales en la filosofía nietzscheana: el del nihilismo, entendido este como un problema de fuerzas o de descenso y retroceso del poder

[12] Cfr. F. Nietzsche, Ecce Homo, op. cit., p. 89.

[13] F. Nietzsche, La ciencia jovial, Caracas: Monte Ávila, 1999, "Prólogo a la segunda edición”, 2, p. 4.

[14] F. Nietzsche, Más allá del bien y del mal, op. cit., Prólogo, p. 21.

[15] Meditaciones, Traducción de Ramón Bach Pellicer, Madrid: Gredos, 2005, II, 17, p. 66.

[16] Disertaciones, Traducción de Paloma Ortiz García, Madrid: Gredos, 1993, III, XXIII, p. 341.

[17] Epístolas morales a Lucilio, Traducción de Ismael Roca Meliá, Madrid: Gredos, 1989, Tomo II, 108, p. 296.

THÉMATA. Revista de Filosofía, Nº51 enero-junio (2015) pp.: 189-206 doi: 10.12795/themata.2015.i51.10 
del espíritu. En la primera obra de Nietzsche, El nacimiento de la tragedia, el filósofo había planteado el asunto de la tragedia y del influjo del socratismo en ella en los términos de una enfermedad que es un signo de declive y de fatiga de los instintos de la civilización griega. En la Segunda Intempestiva, el problema de los estudios históricos también es considerado por el filósofo como una enfermedad que debilita las potencias creadoras e interpretativas de los hombres. Finalmente, y aunque podríamos citar más ejemplos, Nietzsche sostiene en $L a$ genealogía de la moral, una de las obras de su etapa de madurez, que detrás de los ideales de "domesticación" del hombre se expresa "la condición enfermiza del tipo de hombre habido hasta ahora"18 que, a su vez, es resultado del debilitamiento de los instintos por parte de doctrinas morales y ascéticas. Lo que aquí nos interesa señalar es que, al entender el concepto de enfermedad como una cuestión de debilitamiento o parálisis de voluntad o fuerzas, la concepción nietzscheana de la filosofía como medicina entra en claro conflicto con la concepción estoica de la misma.

\section{La crítica nietzscheana a la extirpación estoica de las pasiones}

La primera y más evidente de las diferencias entre ambas posiciones radica en el lugar que ocupan las pasiones en cada filosofía. Es menester tocar este punto ya que, en el pensamiento estoico, las pasiones son consideradas "enfermedades" de las que, precisamente, la filosofía ayuda a librarse; es decir, estas son la principal causa por la cual se requiere una terapia ${ }^{19}$. De igual modo, es necesario aclarar esto, pues autores como Ure sostienen que Nietzsche adoptó la tesis de los estoicos según la cual las pasiones son juicios evaluativos ${ }^{20}$. Una cita en Aurora indicaría esto: "detrás de los sentimientos hay juicios y valoraciones, que han sido transmitidos en forma de sentimientos (inclinaciones, aversiones)"21. Sin embargo, como bien observa el propio Ure, existen profundas diferencias con respecto a la forma nietzscheana de considerar las pasiones y la de los estoicos. Para el filósofo alemán,

[18] F. Nietzsche, La genealogía de la moral, Madrid: Alianza, 2006, III, 13, p. 156.

[19] En el centro de la analogía entre filosofía y medicina se encuentra, como bien señala Foucault, la noción de pathos entendida como enfermedad. Cfr. M. Foucault, La hermenéutica del sujeto, Madrid: Akal, 2005, p. 106 y ss.

[20] Cfr. M. Ure, op. cit., p. 64. Como observa Nussbaum, "en el pensamiento griego acerca de las emociones hay, desde Platón y Aristóteles hasta Epicuro, acuerdo en que las emociones no son simplemente ciegas erupciones de afecto, sacudidas o sensaciones que se reconocen y distinguen unas de otras únicamente por la cualidad sentida en cada una de ellas. A diferencia de apetitos como la sed y el hambre, poseen un importante elemento cognitivo: encarnan maneras de interpretar el mundo". M. Nussbaum, La terapia del deseo, Barcelona: Paidós, 2003, p. 459.

[21] F. Nietzsche, Aurora, Barcelona: Debolsillo, 2009, 35, p. 46.

THÉMATA. Revista de Filosofía, №51 enero-junio (2015) pp.: 189-206

doi: 10.12795/themata.2015.i51.10 
Las pasiones [Leidenschaften] pertenecen a la vida, no es lícito ponerlas bajo sospecha como si fueran perturbadores de la felicidad. Sin amor ni odio, la existencia sería un desierto solitario. Los hombres no desean en absoluto una calma uniforme, buscan excitación y emoción. Provocan por igual placer y dolor. Nada grande se lleva a cabo sin pasión, dice Aristóteles. La vida misma es esa grandeza que no se lleva a cabo sin pasión ${ }^{22}$.

En la tradición estoica iniciada por Zenón y continuada por Crisipo, las pasiones son consideradas "movimientos en contra de la naturaleza del alma"23, impulsos excesivos que constituyen "perturbaciones del alma"24. Si bien los estoicos no plantearon la supresión de todas las emociones, pues distinguieron entre pathé (pasiones violentas) y eupatheiai ${ }^{25}$ (buenas afecciones del ánimo, las cuales pueden ser parte de una vida racional) el postulado de la apatheia implica la extirpación de las pasiones "irracionales" y del deseo.

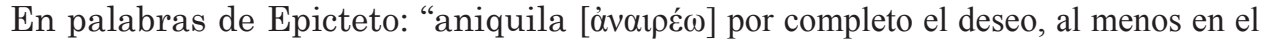
momento presente"26. Así, el sabio estoico, como señala García Gual, "carece de movimientos pasionales: no le mueve la vanidad, ni el placer ni las penas, no se irrita ni se conmueve"27. Esta aspiración por eliminar las pasiones es, en general, fuertemente criticada por Nietzsche a lo largo de toda su obra:

La moral religiosa

El afecto, los apetitos grandes, las pasiones del poder, del amor, de la venganza, de la posesión —: los moralistas quieren extinguirlos, extirparlos, "purificar» el alma de todos ellos.

La lógica es: estos apetitos causan a menudo graves daños - luego son malvados, condenables. El ser humano ha de librarse de ellos: de lo contrario no podrá ser un humano bueno...

(...) Esta forma de pensar, la más miope y la más corrupta de todas, la forma de pensar moral, quiere cegar las grandes fuentes de fuerza, esos torrentes del alma que irrumpen a menudo de manera tan peligrosa y avasalladora, en lugar de poner a su servicio y de sacar rendimiento económico al poder que tienen ${ }^{28}$.

La pretensión de acercar la concepción estoica de la filosofía como terapia y la concepción nietzscheana, entonces, no puede hacerse con base en un punto de encuentro en el cual las pasiones son pensadas como juicios evalua-

[22] F. Nietzsche, Fragmentos póstumos (1875-1882), Madrid: Tecnos, 2008, 9 [1], p. 135. Cursivas nuestras.

[23] Cfr. Vidas de los filósofos ilustres, Traducción de Carlos García Gual, Madrid: Alianza, 2007, VII, 110, p. 373.

[24] Así lo testimonia Estobeo. Cfr. Églogas en Los estoicos antiguos, Introducción, traducción y notas de Ángel J. Cappelletti, Madrid: Gredos, 1996, 333, p. 129.

[25] Vidas de los filósofos ilustres, VII, 117, p. 375.

[26] Manual, Traducción de Paloma Ortiz García, Madrid: Gredos, 1995, 2, 2, p. 184.

[27] C. García Gual, "El sabio epicúreo y el sabio estoico" en Daimon: Revista de filosofía, No. 30, 2003, p. 27.

[28] F. Nietzsche, Fragmentos póstumos (1885-1889), Madrid: Tecnos, 2008, 14 [163], pp. 587-588.

THÉMATA. Revista de Filosofía, Nº51 enero-junio (2015) pp.: 189-206

doi: 10.12795/themata.2015.i51.10 
tivos. De acuerdo con lo visto, el interés primordial de la terapia estoica reside en la supresión de las pasiones violentas que afectan la razón humana y que hace a los hombres infelices, mientras que, para Nietzsche, dicha extirpación es considerada, justamente, como una enfermedad producida por cierto tipo de moral. Así lo dice en La ciencia jovial: "aquellos maestros de la moral que, en primer término y por sobre todo, ordenan al hombre ponerse bajo su propio poder, arrojan con eso sobre él una peculiar enfermedad: específicamente, una continua irascibilidad ante todas las emociones e inclinaciones naturales y, por así decirlo, una especie de escozor"29.

Sin embargo, a pesar de lo dicho antes, Ure afirma que, a finales de la década de 1870, Nietzsche adopta el estoicismo como filosofía. Los argumentos que presenta el autor en el trabajo que hemos citado antes están centrados, sobre todo, en el texto de Aurora y podrían resumirse así: 1) Nietzsche establece que "nuestra" tarea es librarnos de falsas valoraciones sobre los eventos externos que nos producen confusión (turmoil); 2) El filósofo alemán sostiene que, al librarnos de esas valoraciones, prevenimos añadir a nuestro sufrimiento el pensamiento agonizante de que estamos sufriendo un mal o una injusticia; 3) En el aforismo 137 de Aurora, Nietzsche señala que todos los acontecimientos de nuestra vida deberían verse con los mismos ojos con los que se miran los acontecimientos de la vida de otros, lo que es muy cercano a la recomendación que hace Epicteto en el Manual, quien exhorta a comportarnos ante la adversidad como si esta le sucediera a $\operatorname{otros}^{30}$. Estos postulados, según Ure, coinciden con lo que, siguiendo a Sellars, el autor denomina "human stoicism", categoría en la que se inscriben Epicteto y Séneca, para quienes la filosofía es una respuesta "heroica" ante los infortunios, en virtud de la hostilidad del mundo externo. Pero, ¿podemos afirmar por algunas citas tomadas de Aurora que Nietzsche asumió el modelo de la terapia estoica?

En un trabajo titulado Nietzsche's Reading of Epictetus, Brobjer ha mostrado que en el otoño de 1880 Nietzsche leyó el Manual de Epicteto, lo que dio como resultado al menos siete notas en los fragmentos póstumos entre 1880 y 1881, tres referencias en Aurora y una en La ciencia jovial ${ }^{31}$. Es frecuente encontrar en la obra nietzscheana alusiones a las lecturas que realizaba en un momento dado y, ciertamente, los comentarios que hace sobre los planteamientos estoicos que hallamos en Aurora son bastante positivos, pero hay que tomar en cuenta que la valoración que hace Nietzsche de la filosofía estoica casi siempre aparece en contraposición con los ideales cristianos. Por ejemplo, en el aforismo 137 de Aurora que hemos mencionado, y del cual se vale Ure para afirmar su tesis, Nietzsche, en efecto, toma posición a favor de la actitud estoi-

[29] F. Nietzsche, La ciencia jovial, op. cit., 305, p. 178. Cursivas nuestras.

[30] Cfr., Manual, 26, p. 196.

[31] T. Brobjer, "Nietzsche's Reading of Epictetus" en Nietzsche Studien, No. 32, 2003, p. 429.

THÉMATA. Revista de Filosofía, Nº51 enero-junio (2015) pp.: 189-206

doi: 10.12795/themata.2015.i51.10 
ca según la cual deben juzgarse las propias vivencias como si fuesen de otros, pero lo hace al compararla con la actitud cristiana:

¡Por qué duplicar el «yo»! - Contemplar nuestras propias vivencias con los ojos con los que solemos contemplarlas cuando son las vivencias de otros, -tranquiliza mucho y es una medicina aconsejable. Por el contrario, mirar las vivencias de otros y tomarlas como si fueran nuestras -la exigencia de una filosofía de la compasión-, nos destruiría.

De igual forma, en otro aforismo de Aurora, Nietzsche dice lo siguiente: “¡Cómo se han desplazado los juicios definitivos morales! Estos grandes fenómenos de la ética antigua, por ejemplo Epicteto, no sabían nada de la glorificación ahora habitual del pensar en otros, del vivir para otros (...)"32. Asimismo, en el aforismo 139, afirma: “¿Decías que la moral de la compasión es una moral superior a la del estoicismo? ¡Demostradlo!”33. En estos aforismos, queda claro que Nietzsche contrapone el cristianismo (moral de la compasión y del vivir para otros) con el estoicismo (firmeza e individualismo) y que, entre ambos, toma partido por este último: "Y, sin embargo, ¡no elogiaron los estoicos al hombre inflexible, inmisericorde, a quien nada impresionaba, y condenaron al compasivo! ¡Y eso, por supuesto, también era una moral! Una moral que logró algo jmás grande que la nuestra!'’34. Ahora bien, afirmar que Nietzsche practicó el modelo estoico de la filosofía como terapia o medicina a partir de citas en las que contrasta la moral estoica con la cristiana no parece admisible; más aún cuando en varios de sus escritos, anteriores y posteriores a la redacción de Aurora, cuestiona fuertemente al estoicismo. Lo importante aquí no es que Nietzsche piense que la filosofía debe curar al individuo, sino cómo debe hacerlo, pues en ello advertiremos diferencias esenciales entre la Stoa y el filósofo alemán. Para ello, además, debemos preguntar qué motivo condujo a Nietzsche a concebir la filosofía como una suerte de terapia.

El gran descubrimiento nietzscheano, formulado en El nacimiento de la tragedia como el fondo dionisíaco de la existencia, esto es, la ausencia de una realidad metafísica última que sirva como fundamento de todo; la muerte de Dios anunciada por Zaratustra, o la conciencia plena de que "no hay verdad alguna" 35 (en pocas palabras, la llegada del nihlismo) implican, según Ure, la

[32] F. Nietzsche, Aurora, op. cit., 131, pp. 130-131.

[33] Ibid., 139, p. 140.

[34] F. Nietzsche, Fragmentos póstumos (1875-1882), op. cit., 7 [246], p. 713. Cursivas nuestras. Véase también la siguiente nota póstuma: "No hay que confundir dos tipos de moral: una moral con la cual el instinto que ha continuado sano se defiende contra la décadence incipiente - y otra moral con la cual precisamente esta décadence se formula, se justifica y se conduce a sí misma hacia el declive... La primera suele ser estoica, dura, tiránica - el estoicismo mismo fue una moral-freno semejante - la otra es exaltada, sentimental, llena de secretos, en su favor tiene a las mujeres y los «bellos sentimientos»” F. Nietzsche, Fragmentos póstumos (1885-1889), op. cit., 15 [29], pp. 634-635.

[35] "Es giebt keine „Wahrheit“ F. Nietzsche, Fragmentos póstumos (1885-1889), op. cit., 2 [108], p. 108.

THÉMATA. Revista de Filosofía, Nº51 enero-junio (2015) pp.: 189-206

doi: 10.12795/themata.2015.i51.10 
necesidad de algún tipo de terapia que pudiese paliar los efectos de estos hallazgos terribles ${ }^{36}$. En ese sentido,

What Stoicism in particular seemed to offer Nietzsche was precisely a model of philosophical therapy that could eradicate or soothe those negative passions that arise from the human creature's dependence on uncontrollable events and, as a materialist philosophy, could achieve this end without relying on belief in the metaphysical transcendence of the natural world. In Stoic materialism he saw a desire to make happiness (eudaimonia) available to all, within this world, which is not opposed to any superior world ${ }^{37}$.

Las razones que presenta Ure para afirmar que Nietzsche halló en el estoicismo un modelo de terapia filosófica de acuerdo con el problema del nihilismo son cuestionables. En primer lugar, no se puede sostener que el filósofo buscase "erradicar" o "aliviar" las pasiones negativas que se producen ante la incapacidad humana de controlar ciertos eventos. Nos permitiremos reproducir casi en su totalidad un fragmento póstumo del otoño de 1881 -escrito un año después de la lectura del Manual de Epicteto, de acuerdo con Brobjer- en el cual Nietzsche se refiere al estoicismo en los siguientes términos:

Me parece que se conoce mal el estoicismo. Lo esencial de esa manera de ser - eso es lo que es, antes de que la filosofía lo haya conquistado - es su actitud frente al dolor y las representaciones de displacer: se intensifican hasta el extremo cierta gravedad, fuerza de presión y apatía para sentir menos el dolor: el ardid está en la inmovilidad y la insensibili$d a d$, anestética [sic], por lo tanto. El objetivo principal de la educación estoica, eliminar la fácil emotividad, que cada vez sea menor el número de objetos que pueden conmover, que se crea que la mayoría de las cosas que emocionan son despreciables y su valor es nimio, aversión y enemiga a la emotividad, como si la pasión misma fuera una enfermedad o algo indigno: ojo avizor a todas las manifestaciones desagradables y penosas de la pasión — in summa: la petrificación como remedio para el sufrimiento, y todos los nombres sublimes de lo divino, de la virtud concedérselos en adelante a la estatua. (...) Me repugna, y mucho, esa manera de pensar: subestima el valor del dolor (es tan útil y conveniente como el placer), el valor de la emoción y la pasión, al final se ve forzado a decir: me parece bien todo tal como viene, no deseo otra cosa - ya no resuelve ningún estado de necesidad, puesto que su capacidad de sentir estados de necesidad la tiene anestesiada. Esto lo expresa en términos religiosos, en cuanto acuerdo pleno con todos los actos de la divinidad (en Epicteto, p. ej.) ${ }^{38}$.

[36] "In short, Nietzsche recognizes that the debunking of metaphysics must bring with it the specter of embittered nihilism. It is for this reason that Nietzsche confronts a dilemma between truth-which in this context simply means the rejection of metaphysics-and life, or our therapeutic needs. Untruth or error, as he puts it, has become a necessary condition of life". M. Ure, op. cit., p. 67.

[38] F. Nietzsche, Fragmentos póstumos (1875-1882), op. cit., 15 [55], p. 886.

THÉMATA. Revista de Filosofía, No51 enero-junio (2015) pp.: 189-206

doi: 10.12795/themata.2015.i51.10 


\section{El optimismo metafísico y el eudemonismo de la Stoa como formas de nihilismo}

Siguiendo la argumentación de Ure, quien afirma que Nietzsche halló en el estoicismo un camino para lograr la felicidad o eudaimonía, nos encontraremos con varias dificultades que hacen problemático sostener esta tesis. Como sabemos, la filosofía, para los estoicos, no es un mero ejercicio teórico, sino un medio para alcanzar la eudaimonía. La mayoría de las escuelas helenísticas coinciden en este punto, sólo difieren en la concepción de la vida feliz y del sabio. En el caso de los estoicos, la felicidad consiste en vivir de acuerdo con el orden natural del kosmos, al cual se encuentra, asimismo, sometida el alma humana ${ }^{39}$. Pero, aunque Nietzsche sostiene que la filosofía no debe limitarse a ser un ejercicio teórico ${ }^{40}$, sería incorrecto, en nuestra opinión, afirmar que la filosofía, desde la perspectiva nietzscheana, es un medio para alcanzar la felicidad, y menos al modo estoico. En un fragmento póstumo de 1874, el filósofo critica la pretensión de los sistemas morales antiguos por encontrar la felicidad: "los antiguos buscaban la felicidad y la verdad — limitémonos a buscar por todas las partes en las cosas la no-verdad y la desgracia"41. Y es que, para Nietzsche, los estoicos son herederos de la concepción socrática de acuerdo con la cual el conocimiento (la filosofía) es condición necesaria para alcanzar la virtud y, en consecuencia, la felicidad:

En los presocráticos no existe la «infame pretensión de felicidad» que se da a partir de Sócrates. No todo gira ciertamente alrededor del estado de sus almas: pues sobre dicha cuestión

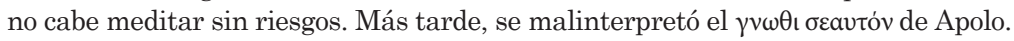

Tampoco parloteaban ni insultaban tanto, ni escribian.

El helenismo debilitado, romanizado, vulgarizado y convertido en algo decorativo, aceptado luego, en calidad de cultura decorativa, como aliado del cristianismo debilitado, y difundido por la fuerza entre los pueblos no civilizados —ésta es la historia de la cultura occidental. El juego de manos está hecho, y lo griego y lo clerical, combinados ${ }^{42}$.

[39] Según el testimonio de Cicerón, el supremo bien, para los estoicos, era "vivir de acuerdo con la naturaleza" [secundum naturam vivere]. Del supremo bien y del supremo mal, Traducción de Víctor-José Herrero, Madrid: Gredos, 1987, II, 34, p. 118.

[40] En la Segunda Intempestiva, Nietzsche escribe lo siguiente: “iEn qué situación tan antinatural, artificial y, en cualquier caso, tan indigna ha de caer en este tiempo que sufre de la formación general la más veraz de todas las ciencias, la diosa desnuda más sincera, la filosofía! En este mundo de obligada uniformidad exterior, ésta no es ya sino el monólogo erudito del paseante solitario, pieza de caza del individuo, secreto de alcoba o chisme insustancial entre académicos ancianos y niños. Nadie se atreve a cumplir la ley de la filosofía consigo mismo, nadie vive filosóficamente con esa sencilla fidelidad que obligaba al hombre antiguo, dondequiera que estuviera y cualesquiera que fueran sus impulsos, a comportarse como estoico en el caso de haberse ya comprometido filosóficamente con la Stoa" F. Nietzsche, Sobre la utilidad y el perjuicio de la historia para la vida, Madrid: Biblioteca Nueva, 2003, 5, p. 79.

[41] F. Nietzsche, Fragmentos póstumos (1869-1874), op. cit., 34 [30], p. 602. Véase también 34 [35], p. 603.

[42] F. Nietzsche, Fragmentos póstumos (1869-1874), op. cit., 6 [14], p. 109. Cfr. también el fragmento 6 [15].

THÉMATA. Revista de Filosofía, Nº51 enero-junio (2015) pp.: 189-206 doi: 10.12795/themata.2015.i51.10 
Aunque en la cita anterior Nietzsche no alude de forma directa a los estoicos, sin duda alguna podemos trasladar esta crítica a ellos, pues ciertamente se propusieron con su filosofía la meta de alcanzar la eudaimonía. Para Zenón, de acuerdo con lo expuesto por Diógenes Laercio, la virtud es autosuficiente para conseguir la felicidad ${ }^{43}$; Epicteto sostenía lo mismo ${ }^{44}$. La impronta socrática en este planteamiento es evidente. Asimismo, es indiscutible el rechazo de Nietzsche por esta concepción: "Yo intento averiguar de qué idiosincrasia procede aquella ecuación socrática de razón $=$ virtud $=$ felicidad: la ecuación más extravagante que existe y que tiene en contra suya, en especial, todos los instintos del heleno antiguo" ${ }^{45}$. Por otra parte, a juicio de Nietzsche, el eudemonismo fue uno de los elementos en la Antigüedad -debilitada o decadenteque hizo posible la aparición del cristianismo. Así lo indica en varios fragmentos póstumos del otoño de 1880:

El fanatismo moral de los filósofos antiguos preparó el camino del cristianismo, se le dio demasiado valor a la salvación del alma. Con relación a la antigüedad somos profundamente inmorales, y esa es nuestra ventaja. Y en comparación con el cristianismo, profundamente irreligiosos ${ }^{46}$.

Y, en otro de la misma fecha, señala que:

La Antigüedad acaba en un quietismo moral y religioso - la Antigüedad cansada y el individuo poderoso y que únicamente se considera a sí mismo importante interpreta los acontecimientos de este mundo con vistas a su salvación, todo lo que sucede tiene un sentido para él. Es la astrología, referida a los Estados, a los acontecimientos naturales, al trato y a la teja en el tejado: todo tiene un sentido, mas sólo para el individuo que consigue hallarlo, cualquier otra cosa es indigna de la atención del sabio. La utilización y el desciframiento moral-religioso del acontecer - todo lo demás era indiferente y despreciable. ¡Había sucumbido el sentido de la ciencia! ${ }^{47}$

Precisamente en esta cita encontramos una de las críticas más fuertes que pone en entredicho la tesis de Ure, quien sostiene que Nietzsche vio en el estoicismo una filosofía materialista capaz de ofrecerle al hombre la felicidad sin apoyarse en una realidad trascendente. En efecto, el estoico acepta el mundo con firmeza como es, pero lo hace en virtud de un orden metafísico que, desde la perspectiva nietzscheana, conduce a un "quietismo religioso" en el cual se atribuye un sentido a la existencia humana. Crisipo, según el testimonio de Plutarco, afirmaba que

[43] Vidas de los filósofos ilustres, VII, 127, p. 379.

[44] "Y si la virtud promete precisamente concedernos la felicidad y la impasibilidad y la serenidad, con toda certeza que el progreso hacia ellas es un progreso hacia cada una de estas cosas" Disertaciones, I, IV, 3-4, p. 67.

[45] F. Nietzsche, Crepúsculo de los ídolos, Madrid: Alianza, 2006, "El problema de Sócrates", 4, pp. $45-46$.

[46] F. Nietzsche, Fragmentos póstumos (1875-1882), op. cit., II, 6 [392], p. 668.

[47] Ibid., 6 [396], p. 668.

THÉMATA. Revista de Filosofía, Nº51 enero-junio (2015) pp.: 189-206

doi: 10.12795/themata.2015.i51.10 
"todo cuanto suceda de un modo u otro en el Universo y en cualquiera de sus partes, sea cual sea, suced[e] en conformidad con aquella [la naturaleza universal] y con la Razón [logos] habita en aquella"48. Asimismo, Marco Aurelio exhortaba a amar el destino en tanto este obedece a un designio divino ${ }^{49}$. Esta concepción del acontecer bajo una clave moral-religiosa se opone a la noción que un auténtico "médico de la cultura", según el filósofo alemán, debe tener. En Más allá del bien y del mal, Nietzsche cuestiona la pretensión estoica de atribuir un "sentido moral" al acontecer: "vuestro orgullo quiere prescribir e incorporar a la naturaleza, incluso a la naturaleza, vuestra moral, vuestro ideal, vosotros exigís que ella sea naturaleza "según la Estoa» y quisierais hacer que toda existencia existiese tan sólo a imagen vuestra" ${ }^{50}$. Por otra parte, este optimismo metafísico es juzgado por Nietzsche como una mala comprensión de Heráclito:

Los estoicos han interpretado a Heráclito superficialmente y lo han comprendido mal. También los epicúreos han contaminado de una manera delicada los rigurosos principios de Demócrito (posibilidades).

Para Heráclito el mundo está sometido a leyes supremas, pero en esto no hay ningún optimismo. ${ }^{51}$

No obstante, es necesario aclarar que Nietzsche no se opone a la búsqueda de algún tipo de consuelo, pues en El nacimiento de la tragedia ya afirmaba que el arte es el único que justifica la existencia ${ }^{52}$ y el que, en cierta forma, le ofrece un consuelo al hombre que ha descubierto que el mundo carece de fundamento; pero también señala que, si el arte ha de fungir como consuelo, no puede ser al modo cristiano del Romanticismo, sino que ha de ser un "arte del consuelo intramundano" ${ }^{53}$ [Kunst des diesseitigen Trostes].

[48] Moralia, Traducción de María Durán y Raúl Caballero, Tomo XI, Madrid: Gredos, 2004, 1050c-d, p. 302.

[49] "Por consiguiente, conviene amar lo que te acontece por dos razones: Una, porque para ti se hizo, y a ti se te asignó y, en cierto modo, a ti estaba vinculado desde arriba, encadenado por causas muy antiguas; y en segundo lugar, porque lo que acontece a cada uno en particular es causa del progreso, de la perfección y ipor Zeus! de la misma continuidad de aquél que gobierna el conjunto del universo". Meditaciones, V, 8, p. 101.

[50] F. Nietzsche, Más allá del bien y del mal, op. cit., 9, p. 30. Hay que aclarar que Nietzsche, en este aforismo, no critica la pretensión de concebir el mundo a partir de un conjunto de ideas pues, como afirma más adelante, la filosofía no es más que la voluntad de "crear el mundo". Lo que, a nuestro juicio, le reprocha el filósofo a los estoicos es concebir que la naturaleza tiene "intenciones", que en realidad "carece de miramientos, de piedad y de justicia".

[51] F. Nietzsche, Fragmentos póstumos (1869-1874), op. cit., 19 [114], p. 370.

[52] "Sólo como fenómeno estético están eternamente justificados la existencia y el mundo" F. Nietzsche, El nacimiento de la tragedia, Madrid: Alianza, 2007, 5, p. 69. Vale aclarar que Nietzsche no entiende el término arte en el sentido estricto de las bellas artes, pues también la filosofía, la religión o la ciencia son consideradas como formas de arte, en tanto son actividades en las que la creación e invención ocupan el puesto central.

[53] F. Nietzsche, El nacimiento de la tragedia, op. cit., "Ensayo de autocrítica", 7, p. 37.

THÉMATA. Revista de Filosofía, Nº51 enero-junio (2015) pp.: 189-206

doi: 10.12795/themata.2015.i51.10 
Este "arte del consuelo intramundano", tal como lo entendemos, se opone radicalmente a la manera estoica de concebir la filosofía como terapia. Hay varios indicios que nos sugieren que los remedios prescritos por los estoicos son, para Nietzsche, precisamente la causa de las peores enfermedades. De hecho, en un fragmento póstumo de 1881, el filósofo afirma que: "el estoicismo del sufrir resignado [gefaßten] es un síntoma de parálisis de la fuerza, frente al dolor se pone en balanza la apatía - falta de heroísmo, que siempre lucha (no sufre), que "va a la busca voluntaria» del dolor ${ }^{54}$ ". En otro fragmento póstumo de 1884, escribe que:

No es nada ser duro como un estoico, con la insensibilidad se ha liberado. Se ha de tener en sí mismo la oposición — la delicada sensación y el contrapoder de no desangrarse, sino de volver a «dirigir hacia lo mejor» toda desgracia de modo plástico ${ }^{55}$.

Este fragmento arroja luces sobre nuestro problema. Tras lo visto, podemos afirmar que Nietzsche estima que el estoicismo es un síntoma de parálisis de fuerza no sólo porque busca la extirpación de las pasiones violentas, sino también porque, al suponer que existe un orden metafísico en el cual todos los sufrimientos humanos encuentran justificación, la voluntad humana queda subordinada a este orden y puede sucumbir a un estado de parálisis o "quietismo" en el cual se carece de la fuerza necesaria para interpretar o crear ficciones ${ }^{56}$. De acuerdo con el filósofo, "la medida de la fuerza de la voluntad la da el grado en que se puede prescindir de un sentido en las cosas, el grado en que se soporta vivir en un mundo sin sentido: porque uno mismo ha organizado una pequeña porción de él" ${ }^{57}$. Con su tesis de la Razón Universal o del logos subyacente a todas las cosas, entonces, el estoicismo no parece ser una alternativa viable desde la perspectiva nietzscheana, en la que la "capacidad de prescindir de mundos ilusorios, salvíficos y consoladores"58 es un signo de fortaleza y de salud.

Ahora bien, detengámonos un momento en aquello que el filósofo alemán llama "quietismo". Según Nietzsche, los filósofos morales de la Antigüedad ven en "la disolución y en el quedarse quietos [im Starrwerden] la salvación"59. En el "quietismo", Nietzsche advierte "mucho extranjerismo - el Oriente, el quietismo,

[54] F. Nietzsche, Fragmentos póstumos (1875-1882), op. cit., 12 [141], p. 852. Cursivas añadidas.

[55] F. Nietzsche, Fragmentos póstumos (1882-1885), Madrid: Tecnos, 2010, 27 [12], p. 620. Cursivas nuestras.

[56] Esta es la descripción que hace Nietzsche del nihilista en un fragmento póstumo de 1887: "la misma especie de hombre, un estadio más pobre, que ya no está en posesión de la fuerza de interpretar, de crear ficciones, constituye el nihilista" F. Nietzsche, Fragmentos póstumos (1885-1889), op. cit., 9 [60], p. 250.

[57] Ibid.

[58] Ibid., p. 251.

[59] F. Nietzsche, Fragmentos póstumos (1869-1874), op. cit., 25 [107], p. 474.

THÉMATA. Revista de Filosofía, Nº51 enero-junio (2015) pp.: 189-206 doi: 10.12795/themata.2015.i51.10 
el invento de la «santidad» surten efecto"60, y quizá por ello se refiera al estoico como un "jeque árabe envuelto en paños y conceptos griegos"61. El "quietismo" podríamos atrevernos a formular- lo observa Nietzsche en la ataraxia o apatheia estoica, medios a través de los cuales el hombre aspira conseguir la tranquilidad de espíritu; pero esto es un síntoma de "degeneración"62, de nihilismo pasivo y, por tanto, de enfermedad, ya que busca un alivio que se apoya en un orden metafísico que no es más que "la nada" o una negación de la realidad.

No es el lugar para debatir si la apatheia o ataraxia estoicas implican, en efecto, un desprecio por "esta realidad"; de hecho, Foucault sostiene que el concepto estoico de askesis no significa renuncia, sino "consideración progresiva del yo", en la que no se fija como meta la preparación para otra realidad ${ }^{63}$. No obstante ello, parece que Nietzsche interpretó que la extirpación estoica de las pasiones envuelve una especie de renuncia: “QQué movía a los antiguos a hacerse estoicos (no teniendo castigos en el infierno ni desprecio por el hombre ni sacralidad divina alguna que les obligara a la renuncia [Entsagung])? (...) El orgullo de ser los primeros en la virtud - envidia, celo" 64 .

Hasta ahora, hemos visto las notables diferencias entre los planteamientos de Nietzsche y los estoicos. Sin embargo, ¿cómo podríamos explicar la doctrina del amor fati sin ningún tipo de acercamiento a la Stoa? ¿Acaso no nos invita Nietzsche no sólo a "aceptar" nuestro destino, sino a amarlo y querer que se repita una y otra vez? ¿No es esto muy cercano a la recomendación de Marco Aurelio? Precisamente, en las doctrinas del amor fati y del eterno retorno nietzscheanas se basa Ure para afirmar que, aunque el filósofo intentó distanciarse del estoicismo, fracasó, pues este pensamiento no es más que un "estoicismo cósmico", en el cual la tarea filosófica es intentar, en la medida de lo posible, alcanzar una perspectiva cósmica en la que se supera el límite entre uno mismo y la naturaleza ${ }^{65}$. A juicio de Ure, el amor fati nietzscheano necesita de "un cierto tipo de indiferencia", pues "amar cada dolor y cada alegría" sólo es posible si se es indiferente ante las cosas. El autor sustenta esta afirmación con base en una nota póstuma de 1881, a propósito del eterno retorno, en la que Nietzsche escribe que "la indiferencia tiene que haber arraigado hondo en nosotros" ${ }^{\prime \prime}$, pero obvia que, antes de esa línea, el filósofo dice que para que ese

\section{[60] Ibid., 25 [106].}

[61] F. Nietzsche, Fragmentos póstumos (1885-1889), op. cit., 11 [294], p. 441.

[62] "Considerar el bien tal como se manifiesta como signo de degeneración — como locura religiosa, por ejemplo, como filantropía, etc.: allí donde el sano egoísmo decae, y se aspira a la apatía o al ascetismo" F. Nietzsche, Fragmentos póstumos (1882-1885), op. cit., 7 [42], p. 186.

[63] Cfr. M. Foucault, Tecnologías del yo, Barcelona: Paidós, 1990, pp. 73-74.

[64] F. Nietzsche, Fragmentos póstumos (1875-1882), op. cit., 7 [207], p. 708. Cursivas nuestras.

[65] Cfr. M. Ure, op. cit., p. 74.

[66] F. Nietzsche, Fragmentos póstumos (1875-1882), op. cit., 11 [141], p. 789.

THÉMATA. Revista de Filosofía, Nº51 enero-junio (2015) pp.: 189-206 doi: 10.12795/themata.2015.i51.10 
pensamiento "abismal" no "nos trastorne" y "la tome contra la vida", "no ha de ser grande nuestra compasión". Una vez más, aparece la contraposición entre el ideal cristiano y el estoico. Pero, más allá de la lectura de una nota en específico, creemos que lo anteriormente expuesto debe servir para no pasar por alto las diferencias entre Nietzsche y los estoicos y que, de forma precipitada, inscribamos al pensador alemán en la corriente del "estoicismo cósmico". Quizás Nietzsche no haya dejado del todo claro cómo es posible aceptar el destino sin la "petrificación" estoica, pero es evidente que, al contrario de lo planteado por los estoicos: 1) los acontecimientos no obedecen a ningún "plano divino" en el cual el sufrimiento "tiene una razón de ser", pues el devenir carece de sentido ${ }^{67}$; es decir, en la aceptación nietzscheana no hay, como en la estoica, un optimismo metafísico; 2) la aceptación del destino no puede llevarse a cabo cercenando las pasiones, y 3) el amor fati no pretende reducir la felicidad del hombre a una tranquilidad que se consigue a través de la disolución de este en la nada.

Así pues, el estoicismo aparece como un modelo de terapia opuesto al nietzscheano que, aunque es preferible a la moral cristiana y puede ser aconsejable en tiempos de crisis $^{68}$, también es un signo de decadencia, debilidad o enfermedad del espíritu. Aquí, es válido preguntar si, como afirma el filósofo en Aurora, la mayor enfermedad de los hombres no habrá surgido de la lucha contra sus enfermedades ${ }^{69}$. En ese sentido, Nietzsche afirma que:

Y por último, en lo que se refiere a la receta de todos estos médicos del alma y a su elogio de una dura y radical curación, cabe preguntar: ¿es esta vida nuestra realmente dolorosa y suficientemente repulsiva, como para cambiarla con ventaja por un modo de vida estoica y petrificación suya? ¡Tan mal no nos encontramos como para tener que encontrarnos mal a la manera estoica! $!^{70}$

El "arte del consuelo intramundano" que debe practicar el filósofo en tanto "médico de la cultura", entonces, no puede consistir en la prescripción de "viejos remedios caseros y de una sabiduría de viejas"

[67] "El movimiento del mundo no tiene ningún estado que sea su meta (...) Yo busco una concepción del mundo que le haga justicia a este hecho: el devenir debe ser explicado sin recurrir a tales intenciones finales: es necesario que el devenir aparezca justificado en todo momento (...); lo presente no se debe justificar en modo alguno en aras de ningún futuro cualquiera o lo pasado en favor de lo presente”. F. Nietzsche, Fragmentos póstumos (1885-1889), op. cit., 11 [72], p. 387.

[68] "El estoicismo puede ser muy aconsejable para los hombres con los que el destino improvisa, para aquellos que viven en tiempos de violencia y dependen de hombres repentinos y mudables. Pero quien de alguna manera alcanza a ver que el destino le permite tejer un largo hilo, hace bien en organizarse epicúreamente; itodos los hombres que realizan un trabajo espiritual lo han hecho hasta ahora! Para ellos sería, en verdad, la pérdida de las pérdidas el perder la sutil irascibilidad y recibir de regalo, por el contrario, la dura piel estoica con púas de erizo" F. Nietzsche, La ciencia jovial, op. cit., 306, p. 179.

[69] Cfr. F. Nietzsche, Aurora, op. cit., A, 52, p. 59.

[70] F. Nietzsche, La ciencia jovial, op. cit., 326, p. 188. Las cursivas son de Nietzsche.

[71] "Todas esas morales que se dirigen a la persona individual para procurarle su «felicidad»,

THÉMATA. Revista de Filosofía, Nº51 enero-junio (2015) pp.: 189-206

doi: 10.12795/themata.2015.i51.10 
a renunciar a las pasiones y al deseo. La aniquilación o disolución de las inclinaciones y deseos humanos, para Nietzsche, puede ocasionar una enfermedad aún mayor que la que se pretendía curar. Apoyarse en la nada (un orden metafísico trascendente) para aceptar el propio destino no es una respuesta valiente ante la vida ${ }^{72} \mathrm{y}$, además, constituye la negación de la sabiduría trágica griega ${ }^{73}$ que, según Nietzsche, había descubierto que la existencia carece de un fundamento. Ahora bien, que para aceptar el destino sin depender de una supuesta Razón Universal se necesite de algún tipo de firmitas, parece claro; mas esa firmeza o disciplina de espíritu no ha de ser como la estoica, inhibidora de las potencias del hombre, sino que más bien debe traducirse en una plasticidad que encuentra en la adversidad múltiples sentidos e impulsos para continuar de pie ante el devenir sin sucumbir en explicaciones que postulen un único sentido, metafísico y ajeno al hombre.

según se dice, qué otra cosa son que propuestas de comportamiento en relación con el grado de peligrosidad en que la persona individual vive a causa de sí misma; recetas contra sus pasiones, sus inclinaciones buenas y malas, dado que éstas tienen voluntad de poder y quisieran desempeñar el papel de señor; ardides y artificios pequeños y grandes que desprenden el rancio olor propio de viejos remedios caseros y de una sabiduría de viejas (...) ya se trate de aquella indiferencia y aquella frialdad de estatuas frente a la ardorosa necedad de los afectos que los estoicos aconsejaban y prescribian como medicina; ya de aquel dejar-de-reír y dejar-de-llorar de Spinoza (...)" F. Nietzsche, Más allá del bien y del mal, op. cit., 198, pp. 137-138. Cursivas añadidas.

[72] "Con muchos polvillos se puede hacer cobarde al valiente, pero también valiente al cobarde: Dependencia cósmica” F. Nietzsche, Fragmentos póstumos (1882-1885), op. cit., 9 [32], p. 247. Si, como dice Nietzsche, "la verdad es fea", es evidente que para él la sabiduría sólo es accesible al "valeroso", al "guerrero" (Cfr. F. Nietzsche, Así habló Zaratustra, Madrid: Alianza, 2007, "Del leer y el escribir", p. 74). Nos atrevemos a aventurar la hipótesis de que el hombre valiente, desde la perspectiva nietzscheana, es aquel que acepta el destino sin acudir a consuelos metafísicos.

[73] "He puesto el conocimiento por delante de imágenes tan terribles, que toda "satisfacción epicúrea» es imposible. Sólo el placer dionisíaco basta - Yo HE SIDO EL PRIMERO EN DESCUBRIR LO TRÁGICO. Los griegos, debido a su superficialidad moralista, lo entendieron mal. ¡Tampoco la resignación es una doctrina de la tragedia! — sino ¡un malentendido de la misma! ¡El anhelo de la nada es la negación de la sabiduría trágica, su contrario" F. Nietzsche, Fragmentos póstumos (18821885), op. cit., 25 [95], p. 471.

THÉMATA. Revista de Filosofía, Nº51 enero-junio (2015) pp.: 189-206 doi: 10.12795/themata.2015.i51.10 


\section{Referencias bibliográficas:}

Brobjer, T.: "Nietzsche's Reading of Epictetus" en Nietzsche Studien, No. 32, 2003.

Cappelletti, A. (tr.): Los estoicos antiguos. Introducción, traducción y notas de Ángel J. Cappelletti, Madrid: Gredos, 1996.

Cicerón: Del supremo bien y del supremo mal. Traducción de Víctor-José Herrero, Madrid: Gredos, 1987.

Diógenes Laercio: Vidas de los filósofos ilustres. Traducción de Carlos García Gual, Madrid: Alianza, 2007.

Elventon, R.: "Nietzsche's Stoicism: The Depths Are Inside" en Nietzsche and Antiquity, editado por Paul Bishop, Rochester, NY: Camden House, 2004, pp. 192-203.

Epicteto: Disertaciones. Traducción de Paloma Ortiz García, Madrid: Gredos, 1993.

Gredos, 1995. , Manual. Traducción de Paloma Ortiz García, Madrid:

Foucault, M.: La hermenéutica del sujeto, Madrid: Akal, 2005. Tecnologías del yo, Barcelona: Paidós, 1990.

García Gual, C.: "El sabio epicúreo y el sabio estoico" en Daimon: Revista de filosofía, No. 30, 2003, pp. 23-31.

Hutter, H. (ed): Nietzsche's Therapeutic Teaching, New York: Bloomsbury, 2013.

Marco Aurelio: Meditaciones. Traducción de Ramón Bach Pellicer, Madrid: Gredos, 2005.

Nabais, N.: Nietzsche and the Metaphysics of the Tragic, Continuum: London/New York, 2002.

Nietzsche, F.: Así habló Zaratustra. Traducción de Andrés Sánchez Pascual. Madrid: Alianza, 2007.

Debolsillo, 2009.

Aurora. Traducción de Genoveva Dieterich, Barcelona: chez Pascual. Madrid: Alianza, 2006.

Crepúsculo de los ídolos. Traducción de Andrés SánMadrid: Alianza, 2006.

Ecce Homo. Traducción de Andrés Sánchez Pascual, Sánchez Pascual. Madrid: Alianza, 2007.

El nacimiento de la tragedia. Traducción de Andrés Fragmentos póstumos (1869-1874), 2 2a edición. Traducción, introducción y notas de Luis E. De Santiago Guervós, Madrid: Tecnos, 2010, , Fragmentos póstumos (1875-1882). Traducción, introducción y notas de Manuel Barrios y Jaime Aspiunza. Madrid: Tecnos, 2008. 
, Fragmentos póstumos (1882-1885). Traducción, introducción y notas de Diego Sánchez Meca y Jesús Conill. Madrid: Tecnos, 2010. , Fragmentos póstumos (1885-1889). Traducción, introducción y notas de Juan Luis Vermal y Joan B. Llinares. Madrid: Tecnos, 2008. Caracas: Monte Ávila, 1999. La ciencia jovial, $3^{\text {a }}$ edición. Traducción de José Jara. , La genealogía de la moral. Traducción de Andrés Sánchez Pascual. Madrid: Alianza, 2006.

chez Pascual, Madrid: Alianza, 2007. , Más allá del bien y del mal. Traducción de Andrés Sán, Sobre la utilidad y el perjuicio de la historia para la vida [II Intempestiva], $2^{\text {a }}$ edición. Edición, traducción y notas de Germán Cano. Madrid: Biblioteca Nueva, 2003.

Nussbaum, M.: "Pity and Mercy: Nietzsche's Stoicism" en Nietzsche, Genealogy, Morality, editado por Richard Schacht, Berkeley: University of California Press, 1994, pp. 139-167. , La terapia del deseo, Barcelona: Paidós, 2003.

Plutarco: Moralia. Traducción de María Durán y Raúl Caballero, Tomo XI, Madrid: Gredos, 2004.

Sandbach, F.H.: The stoics, 2a edición, Idianapolis: Hackett, 1989.

Séneca: Epístolas morales a Lucilio. Traducción de Ismael Roca Meliá, Madrid: Gredos, 1989.

Ure, M.: "Nietzsche's Free Spirit Trilogy and Stoic Therapy" en Journal of Nietzsche Studies, No. 38, 2009, pp. 60-84. 